\title{
Prospects for the replacement of steel parts for oil and gas equipment by aluminium parts
}

\author{
V. N. Kuskov \& N. F. Kolenchin \\ Tyumen State Oil \& Gas University, Russia
}

\begin{abstract}
The problem of reducing the mass of modern equipment while increasing its working properties is challenging today. The application of aluminium alloys in the oil and gas industry creates an oxide layer on their surfaces, with wear resistance of up to the level (or above) that of the steel materials that are currently applied. The effects of ozone and the use of ultrasound to increase the hardness, wear resistance and corrosion resistance of the anode coating have been determined. Three facilities for the anodizing of aluminium and its alloys have been patented. The injection of ozone into the air mixture increases the thickness of the alumina by $45-53 \%$ and an additional application of the ultrasound increases the microhardness of the coating by almost a factor of 1.5. The facts are explained by the increase of the proportion of the alumina crystals in the coating. The structure of the anode film has been studied with an increase of more than 2200 times. First, the possibility of the formation of secondary channels due to the amorphous component of the coating has been established. On the basis of the obtained data, a technology for anodizing the real parts of the oil and gas equipment made from aluminium alloys instead of steel equipment has been developed. The nozzle and the mixing chamber of the jet pump, the sliding bearing collar, safety shirts, guide vanes and intersection pump packings for maintaining the reservoir pressure have been manufactured from the alloy D16. Anodized aluminium parts are successfully operated in an aggressive environment without shock loads. The magnitude of wear decreased by more than a factor of seven in comparison with the serial parts.
\end{abstract}

Keywords: aluminium alloys, ozone, ultrasound, anodizing, microhardness, wear. 


\section{Introduction}

The challenges of the mass reduction of equipment, reliability enhancement and intensification of operation have always been crucial. One of the ways to meet these challenges in the oil and gas industry is with the replacement of steel parts for aluminium parts $[1,2]$ that are further exposed to anodization in order to enhance their surface properties.

\section{Materials and research techniques}

Samples of the alloy D16 with the dimensions of $30 \mathrm{~mm} \times 30 \mathrm{~mm} \times 3 \mathrm{~mm}$ have been used. Anodizing is achieved by exposing the alloy to $5 \%$ sulfuric acid at the temperature $(0 \pm 1)^{\circ} \mathrm{C}$, using the patented facilities [3-5]. An electrolyte has been blown through with air or its mixture with $2 \mathrm{mg} / \mathrm{l}$ of ozone. We tested a blow through with the ozone-air mixture with simultaneous ultrasonic exposure at a frequency of $2.2 \times 10^{6} \mathrm{~Hz}$ through an electrolyte.

The microhardness (HV) of the anode film was measured on transverse sections through the PMT-3 with $0.49 \mathrm{~N}$ load. The thickness was tested metalographically with a MIM-7 microscope and a "Kostanta K-7" thickness gauge. Wear resistance was estimated by the reduction in the thickness of the coating on the "Shlif". X-ray studies were conducted on the DRON-3 $\mathrm{Ko}_{\mathrm{Ka}}{ }^{-}$ radiation in the angular ranges from $20^{\circ}$ to $60^{\circ}$.

\section{Results and discussion}

Figure 1 shows the dependence of the thickness of the oxide coating during the anodization process and Table 1 shows the results of the mechanical tests.

Use of the ozone-air mixture increases the finite thickness of the aluminium oxide from $45 \%$ to $53 \%$. In the case of air blow an increase of coating stabilizes by the 40th minute of oxidizing, but in use of ozone it lasts up to 50 minutes, i.e. the oxidation potential of the ozone-enriched mixture is higher. Use of ultrasound exposure to the electrolyte decreases the intensity of formation of the oxide coating and its finite thickness decreases by $10-14 \%$ compared with the use of the ozone-air mixture. Apparently, the fretted effect of the electrolyte is accelerated or the cavitation wear of the outer surface of the oxide film is affected; therefore, the microhardness and wear resistance increase substantially.

The increase of microhardness of the coating with enrichment by ozone of the gas mixture is caused by the increase of the concentration of the crystals of $\gamma-\mathrm{Al}_{2} \mathrm{O}_{3}$ in the coating. Moreover, the share of the amorphous component in the coating decreased to that shown by a reduction of the halo on roentgenograms in the range of corners from $20^{\circ}$ to $40^{\circ}$ testifies.

In Figure 2 the general view of the channeled coating with channels that are perpendicular to the initial surface of the alloy D16 is pictured. In Figure 3(a) the formation of the secondary channel appearing as a result of dissolution, most likely by an amorphous component of the coating not described in scientific and 
technical literature, is shown. Branching of the channel has started after its overlapping by its crystal particle visible in Figure 3(b).

On the basis of the obtained data there has been developed a technology of anodizing of real parts of the oil and gas equipment made from aluminium alloys instead of steel. The nozzle and the mixing chamber of the jet pump, the sliding bearing collar, safety shirts, guide vanes and intersection pump packings for maintaining reservoir pressure have been manufactured from alloy D16. Anodized aluminium parts have operated successfully in an aggressive environment without shock loads. The magnitude of the wear decreased by more than a factor of seven in comparison with the serial parts.

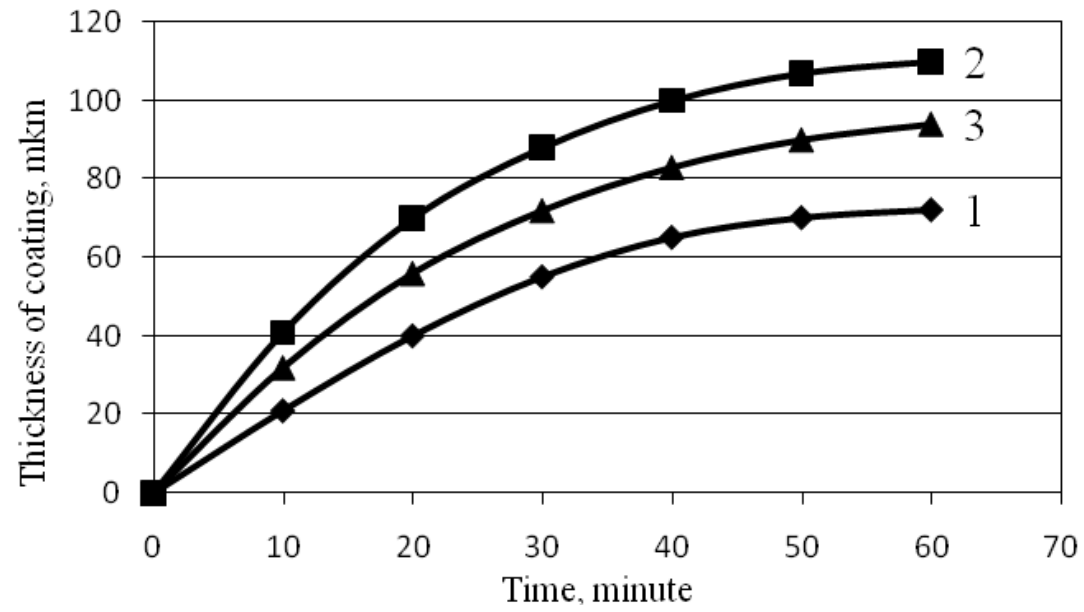

Figure 1: Change in the thickness of the anode coating on the alloy D16 produced by air blowing through an electrolyte (1), ozone-air mixture (2) and ozone-air mixture under ultrasound exposure (3).

Table 1: Results of the mechanical tests.

\begin{tabular}{|l|c|c|}
\hline \multicolumn{1}{|c|}{ Properties of anodization } & $\begin{array}{c}\text { Microhardness, } \\
\mathrm{MPa}\end{array}$ & Wear, mkm \\
\hline Air blowing through an electrolyte & 5500 & 19 \\
\hline Ozone-air mixture blow & 6850 & 8 \\
\hline $\begin{array}{l}\text { Ozone-air mixture blow under } \\
\text { ultrasonic exposure }\end{array}$ & 8220 & 5 \\
\hline
\end{tabular}




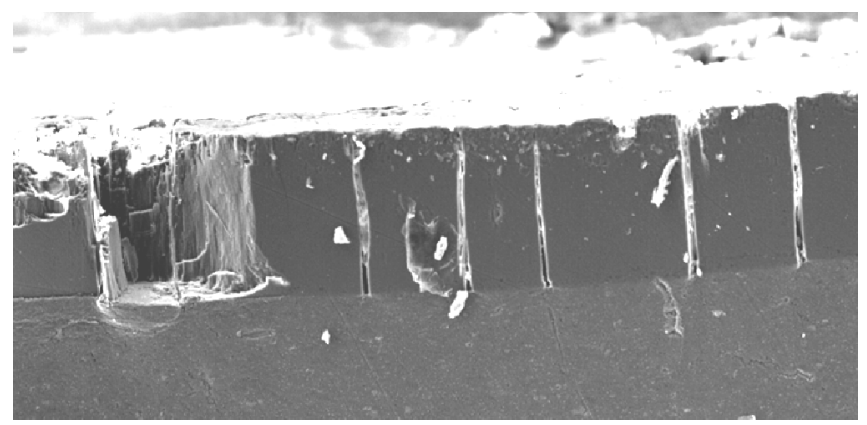

Figure 2: $\quad$ General view of coating with channels (95-fold increase).

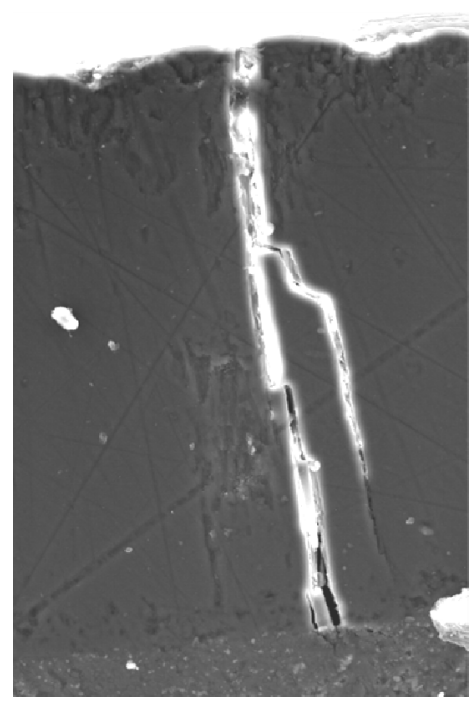

(a)

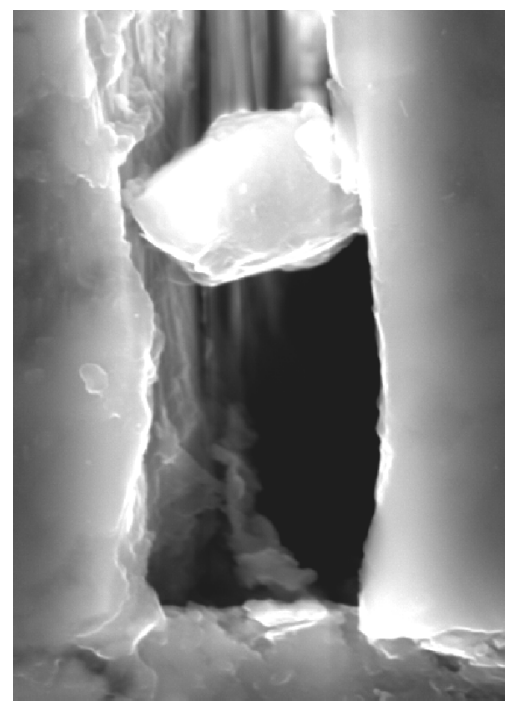

(b)

Figure 3: Occurrence of a secondary channel in the coating $(\mathrm{a})(\times 600)$ and a particle launched by it (b) $(\times 8,000)$.

\section{Conclusions}

1. It has been found that using ozone in air mixture for blowing through an electrolyte when anodizing the alloy D16 in 5\% water solution of sulfuric acid increases the finite thickness of the oxide coating by $45-53 \%$ and simultaneous ultrasound exposure with the ozone-air mixture blowing through an electrolyte only by $30-35 \%$, although in the latter case it increases the microhardness of the anode layer up to $8,220 \mathrm{MPa}$. 
2. The increase in microhardness of the coating on aluminium alloys with enrichment by ozone of a gas mixture is caused by a reduction in the share of amorphous components and an increase in the concentration of $\gamma-\mathrm{Al}_{2} \mathrm{O}_{3}$ crystals in the coating.

3. The wear resistance of anode coatings on the alloy D16, produced by a combination of ultrasonic exposure with blow through an electrolyte by the ozone-air mixture, increased by a factor of 1.7 in comparison with the coatings produced in the presence of ozone and by a factor of 3.7 in comparison with coatings without the use of ozone. The outcomes demonstrate prospects for the use of ultrasound in combination with blowing through an electrolyte of the ozone-air mixture when anodizing aluminium alloys.

\section{References}

[1] Fedorov V.A., Kan A.G., Maksutov R.A. Surface Hardening of oil and gas equipment by technique of microarc oxidation, Moscow, VNIIOENG, 1989. $48 \mathrm{p}$.

[2] Kolenchin N.F., Kuskov V.N. Increase in term of operation of oil-field equipment due to material replacement // Proceedings of Samara Scientific Centre of Russian Academy of Sciences. 2011. Vol. 13. № 1 (2), pp. 456-458.

[3] Patent of the Russian Federation for useful model № 114056, C25D 11/04. Facility for anodizing of aluminium and its alloys/Kolenchin N.F., Kuskov V.N., Safronov A.V., Schadrina P.H. //Bulletin № 7 from 10.03.12; application 19.09.2011, № 2011138397.

[4] Patent for useful model № 116501, C25D 11/06. Facility for anodizing of aluminium and its alloys / Kolenchin N.F., Kuskov V.N., Schadrina P.H.: //Bulletin № 15 from 27.05.2012; application 30.12.2011, № 2011154687.

[5] Patent for useful model № 116500, C25D 11/02. Facility for anodizing of aluminium and its alloys / Kolenchin N.F., Kuskov V.N., Safronov A.V.:// Bulletin № 15 from 27.05.2012; application 10.01.2012, № 2012100106. 